\title{
Seasonal and annual variation of carbon dioxide surface fluxes in Helsinki, Finland, in 2006-2010
}

\author{
L. Järvi ${ }^{1}$, A. Nordbo ${ }^{1}$, H. Junninen ${ }^{1}$, A. Riikonen ${ }^{2}$, J. Moilanen ${ }^{1}$, E. Nikinmaa ${ }^{2}$, and T. Vesala ${ }^{1}$ \\ ${ }^{1}$ Department of Physics, University of Helsinki, P.O. Box. 48, University of Helsinki, Finland \\ ${ }^{2}$ Department of Forest Sciences, University of Helsinki, P.O. Box 27, University of Helsinki, Finland
}

Correspondence to: L. Järvi (leena.jarvi@helsinki.fi)

Received: 8 February 2012 - Published in Atmos. Chem. Phys. Discuss.: 28 March 2012

Revised: 31 July 2012 - Accepted: 6 September 2012 - Published: 21 September 2012

\begin{abstract}
Five years of carbon dioxide exchange measured with the eddy covariance technique at the world's northernmost urban flux station SMEAR III located in Helsinki, Finland, were analyzed. The long-term measurements and high-latitude location enabled us to examine the seasonal and annual variations of $\mathrm{CO}_{2}$ exchange, and to identify different factors controlling the measured exchange. Online traffic counts and soil respiration measurements were utilized in the study. Furthermore, the advantage of the station is that the complex surrounding area enables us to distinguish three different surface cover areas that can be evaluated separately. We also tested different methods (artificial neural networks and median diurnal cycles) to fill gaps in $\mathrm{CO}_{2}$ flux time series and examined their effect on annual emission estimates.

The measured fluxes were highly dependent on the prevailing wind direction with the highest fluxes downwind from a large road and lowest downwind from the area of high fraction of vegetation cover. On an annual level, the area of the road emitted $3500 \mathrm{~g} \mathrm{C} \mathrm{m}^{-2}$ whereas the area of high fraction of vegetation cover emitted only $870 \mathrm{~g} \mathrm{C} \mathrm{m}^{-2}$ showing the effect of surface cover to be large in urban areas. Seasonal differences in the $\mathrm{CO}_{2}$ exchange downwind from the road were mainly caused by reduced traffic rates in summer, whereas in other directions seasonality was more determined by vegetation activity. Differences between the gap filling methods were small, but slightly better $\left(0.6 \mu \mathrm{mol} \mathrm{m}^{-2} \mathrm{~s}^{-1}\right.$ smaller RMSE) results were obtained when the artificial neural network with traffic counts was used instead of the one without traffic network and method based on median diurnal cycles. The measurement site was a net carbon source with average annual emissions of $1760 \mathrm{~g} \mathrm{C} \mathrm{m}^{-2}$, with a biased error of $6.1 \mathrm{~g} \mathrm{C} \mathrm{m}^{-2}$ caused by the gap filling. The annual value varied $16 \%$ between the different years.
\end{abstract}

\section{Introduction}

Carbon dioxide $\left(\mathrm{CO}_{2}\right)$ is one of the most important greenhouse gases warming our atmosphere. Even though urban areas cover only a small fraction of Earth's land area, most of the $\mathrm{CO}_{2}$ emissions originate from cities due to human activities (Rosenzweig et al., 2010). In addition to direct anthropogenic emissions, urban areas affect the exchange of $\mathrm{CO}_{2}$ via changes in land use as areas of vegetation cover, that are normally carbon sinks are replaced with urban land uses. In Helsinki (Finland), $\mathrm{CO}_{2}$, methane and nitrogen dioxide are the most important greenhouse gases emitted by human activities. Half of their emissions originate from heating, one quarter from electricity and the remaining quarter from road traffic (Lounasheimo and Niemi, 2010). These annual percentages, as generally $\mathrm{CO}_{2}$ emissions in a city and national level, are calculated from fossil fuel consumption of the various processes. This bottom-up approach is considered to be fairly accurate on an annual level, but lacks the information about the spatial and temporal variations of the emissions and sinks of $\mathrm{CO}_{2}$ in different urban land uses. These are important for city planning strategies and also for getting realistic estimations for the net $\mathrm{CO}_{2}$ emissions emitted by the urban ecosystem. Also more information about the accuracy of the bottom-up approach is needed. So far successful comparisons between the emission inventories and direct meteorological measurements have been made e.g. in a city scale in London, UK (Helfter et al., 2011), and in a residential area in Vancouver, Canada (Christen et al., 2011). Despite the different measurement surroundings, both studies showed good agreement between the two approaches. 
The most direct way to measure the exchange of $\mathrm{CO}_{2}$ between the surface and the atmosphere is the eddy covariance (EC) technique (Lee et al., 2004). The EC technique has been widely used above vegetated surfaces (e.g. Baldocci, 2003), and within the last ten years EC measurements have been made in several urban areas with varying measurement period lengths (Velasco and Roth, 2010). So far only few studies, all published within the last year, have covered several years of $\mathrm{CO}_{2}$ flux measurements (Bergeron and Strachan, 2011; Christen et al., 2011), and the only published longterm ( $5 \mathrm{yr}$ ) study is from a highly vegetated measurement site in Baltimore, USA (Crawford et al., 2011). Due to the lack of long-term studies, understanding the year-to-year variability of $\mathrm{CO}_{2}$ exchange and representativeness of the analyzed periods remains limited.

Deriving realistic estimates for yearly $\mathrm{CO}_{2}$ emissions in urban environments from EC measurements is not straightforward due to the complex combination of emission sources and sinks inside the source areas. Usage of simple gap filling techniques including parameterizations based on the soil temperature and photosynthetically active radiation (PAR) (Falge et al., 2001) are not likely valid. This parameterization was used in Baltimore (Crawford et al., 2011), where the method is more acceptable due to the high fraction of vegetated surface area compared to more built-up environments. Other gap filling methods used in urban areas include look-up tables and monthly diurnal cycles (Moriwaki and Kanda, 2004; Christen et al., 2011), whereas in some studies the monthly and annual values have been derived from daily average fluxes (Bergeron and Strachan, 2011; Helfter et al., 2011). Gap filling of flux time series using artificial neural networks (ANN) has become increasingly popular (Falge et al., 2001; Papale and Valentini, 2003; Moffat et al., 2007). ANN has also shown promising results in urban environments since it can fill gaps without any knowledge of the complex nature of carbon sinks and sources. In Münster and Essen, Germany, the radial basis networks (RBS) have been used (Schmidt et al., 2008; Kordowski and Kuttler, 2010), whereas generalized regression neural networks (GRNN) was used in Melbourne, Australia (Coutts et al., 2007). Despite the various methods to fill gaps in $\mathrm{CO}_{2}$ flux time series, the effect of these have not been studied or errors related to the gap filling have not been given. In Baltimore, variations in annual estimations between the studied years were considered to represent errors related to their gap filling method (Crawford et al., 2011). Realistic annual emissions and related errors are important when emissions from different cities are compared, and when values are used as input variables in regional and global models.

In this study we examine the exchange of $\mathrm{CO}_{2}$ from the northernmost urban flux site using five years of measurements in 2006-2010. The purpose is to study the seasonal and annual variations of the $\mathrm{CO}_{2}$ exchange and to distinguish the most important controlling factors. In addition, for the first time the impact of different gap filling methods, in-

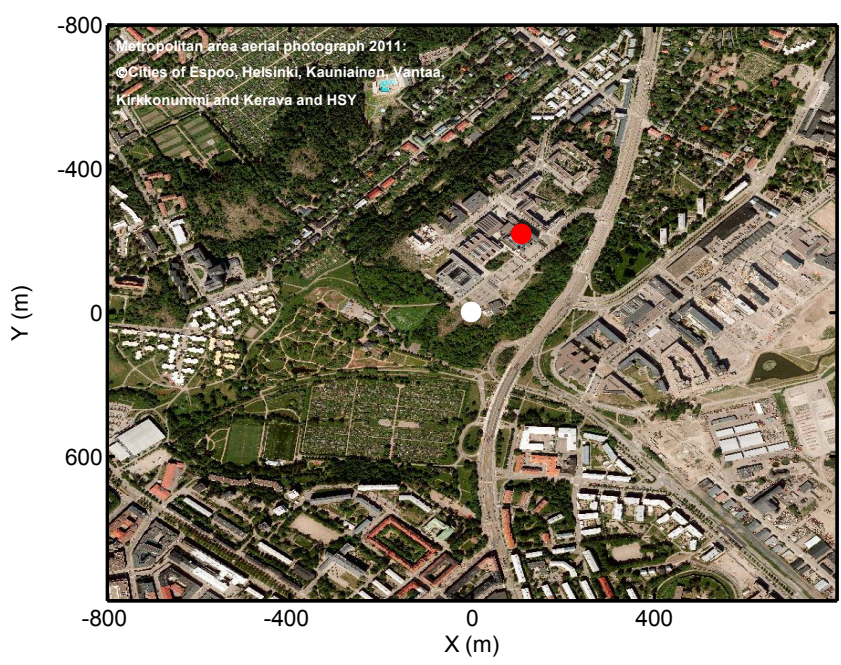

Fig. 1. Aerial photograph of the SMEAR III station. The measurement tower is marked with a white circle and the roof, where additional measurements are carried out, is marked with red circle.

cluding neural networks and median diurnal cycles, on the annual carbon exchange in an urban area are examined and errors related to the emissions are studied. Particularly, the importance of traffic counts in the gap filling procedure is tested.

\section{Methods}

\subsection{Measurement site}

The measurements were carried out at the urban measurement station SMEAR III in Helsinki Finland (Järvi et al., 2009a) in January 2006-December 2010. Part of the station is located in the University of Helsinki campus area around five kilometers North-East from the Helsinki City Centre. Measurements are made on top of a $31 \mathrm{~m}$ high lattice tower $\left(60^{\circ} 12.17^{\prime} \mathrm{N}, 24^{\circ} 57.671^{\prime} \mathrm{E}, 26 \mathrm{~m}\right.$ a.s.l. $)$ and on the roof of one of the University of Helsinki buildings at a height of $29 \mathrm{~m}$ (Fig. 1). The measurement site belongs to the urban climate zone six with mixed use with large buildings in open landscape (Oke, 2004). According to the prevailing wind direction, the measurement surroundings around the tower can be divided into three areas: built, road and vegetation, each representing the typical surface cover on the area (Table 1). The built area is covered with university campus buildings and Finnish Meteorological Institute (mean height $20 \mathrm{~m}$ ) in the vicinity of the measurement tower, and a single family house area with a high areal fraction of vegetation is located further away (Fig. 1). A heavily trafficked road with 44000 vehicles per workday (Lilleberg and Hellman, 2011) passes the road area with the closest distance between the road and the tower being $150 \mathrm{~m}$. There are also large crossroads with several traffic lights located in the area. The area between the 
Table 1. Surface cover fractions of paved surface $\left(f_{\text {paved }}\right)$, buildings $\left(f_{\text {built }}\right)$ and vegetation $\left(f_{\text {veg }}\right)$ inside an $800 \mathrm{~m}$ radius circle around the measurement tower. Fractions are also given for the different surface cover areas: built, road and vegetation.

\begin{tabular}{lccc}
\hline & $f_{\text {paved }}$ & $f_{\text {built }}$ & $f_{\text {veg }}$ \\
\hline All & 0.22 & 0.34 & 0.44 \\
Built $\left(320-40^{\circ}\right)$ & 0.18 & 0.39 & 0.43 \\
Road $\left(40-180^{\circ}\right)$ & 0.30 & 0.29 & 0.41 \\
Vegetation $\left(180-320^{\circ}\right)$ & 0.15 & 0.35 & 0.50 \\
\hline
\end{tabular}

road and the tower is covered with deciduous forest and the area behind the road is covered with combined mix of residential and commercial buildings. In the vegetation area the fraction of vegetation is high since the University Botanical Garden and City Allotment Garden are located in the area. The closest buildings are $400 \mathrm{~m}$ and the nearest larger road is $900 \mathrm{~m}$ away from the tower in the vegetation area.

We examined five full years of $\mathrm{CO}_{2}$ flux data from 2006 to 2010 and these were divided into thermal seasons. Thermal summer starts when the 5-day running mean daily air temperature increases above 10 degrees. Similarly thermal winter starts when the 5-day running mean daily temperature drops below zero. Thermal fall and spring fall in between. The length of the thermal seasons varies greatly from year to year as can be seen from Fig. 2. Snow days were determined from the measured surface albedo: the ground was considered to be covered with snow when the daytime (11:00-14:00 LT) albedo was above 0.3.

\subsection{Instrumentation and quality assurance}

\subsection{1 $\mathrm{CO}_{2}$ exchange}

The $\mathrm{CO}_{2}$ exchange was measured on top of the measurement tower using the EC technique. The setup consisted of an ultrasonic anemometer (USA-1, Metek GmbH, Germany) to measure all three wind speed components and sonic temperature, and open- and closed-path infrared gas analyzers (LI7500 and LI-7000, respectively, LI-COR, Lincoln, Nebraska, USA) to measure $\mathrm{CO}_{2}$ density and mixing ratio, respectively. The setup was located on a horizontal boom, $1.3 \mathrm{~m}$ southwest from the tower. The open-path analyzer was mounted $0.2 \mathrm{~m}$ away from the anemometer and was tilted $30^{\circ}$ to allow rainwater to drip off. For the closed-path analyzer, air samples were taken $0.13 \mathrm{~m}$ below the anemometer center and air was drawn to the analyzer through a $40 \mathrm{~m}$ long steel tube with an inner diameter of $8 \mathrm{~mm}$. The flow rate in the tube was $171 \mathrm{~min}^{-1}$ to ensure turbulent flow, and the sampling line was heated to avoid condensation of water vapor initially with a power of $4 \mathrm{~W} \mathrm{~m}^{-1}$ and since 8 September 2010 with a power of $16 \mathrm{~W} \mathrm{~m}^{-1}$. The frequency of the EC measurements was $10 \mathrm{~Hz}$ and the raw data were stored for later post-processing.

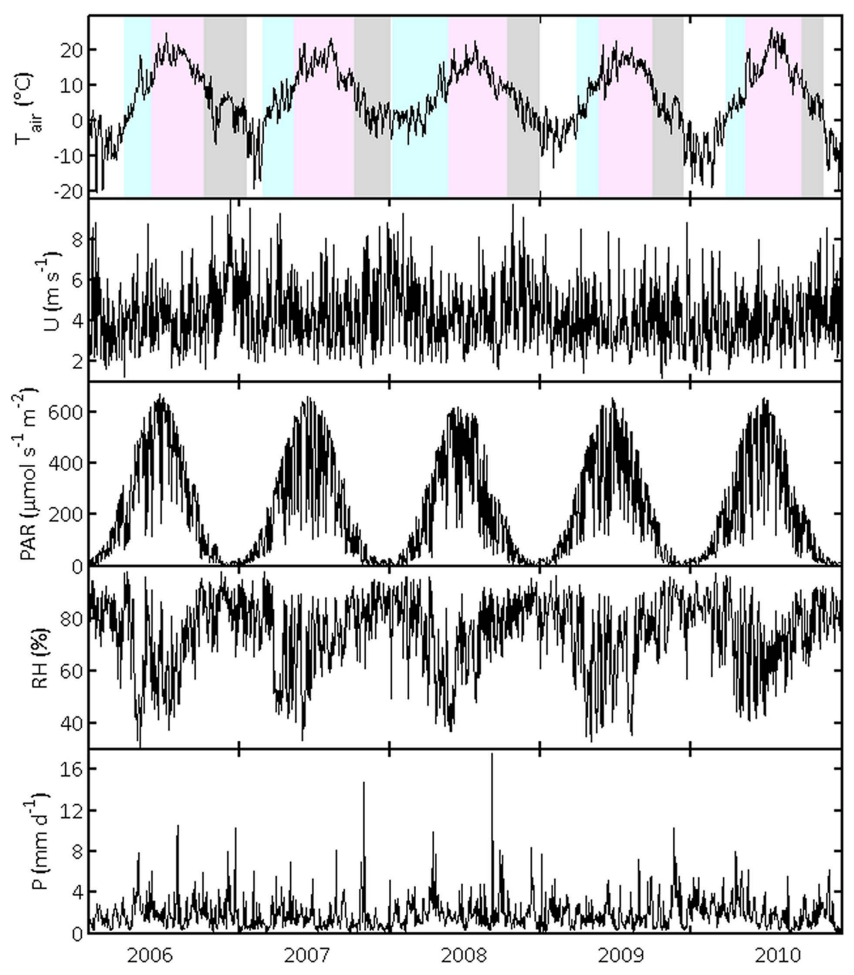

Fig. 2. Daily air temperature $\left(T_{\text {air }}\right)$, wind speed $(U)$, photosynthetically active radiation (PAR), relative humidity $(\mathrm{RH})$ and precipitation $(P)$ during the five years of measurements. The colored areas in the upper panel show the thermal seasons: winter = white, spring $=$ green, summer $=$ red and grey $=$ fall.

Before the calculation of the final 30-min fluxes, despiking, linear detrending and a 2-dimensional coordinate rotation were applied to the raw data. Flux values were calculated using the maximum covariance method and those measured by open-path were corrected for temperature and humidity fluctuations (Lee et al., 2004). Fluxes measured with both setups were corrected for losses at the high and low-frequency ends of co-spectra. Detailed information about the data postprocessing can be found in Nordbo et al. (2012).

For the first 18 months, $\mathrm{CO}_{2}$ flux measured with the openpath analyzer was used in the analysis. In July 2007, the measurement setup was supplemented with a closed-path analyzer and due to better data coverage and performance (Järvi et al., 2009b), $\mathrm{CO}_{2}$ flux measured with the closed-path was used for rest of the analyzed period. In order to avoid bias in the results, open-path $\mathrm{CO}_{2}$ was corrected for the sensor surface heating (e.g. Burba et al., 2008; Järvi et al., 2009b) with a method described in Nordbo et al. (2012). After the correction, $\mathrm{CO}_{2}$ fluxes measured with open- and closed-path analyzers were close to each other with a slope $=0.98$, offset $=0.0, \mathrm{RMSE}=1.3 \mu \mathrm{mol} \mathrm{m}{ }^{-2} \mathrm{~s}^{-1}$ and $R^{2}=0.94$.

Data coverage after post-processing varied largely between the different years and seasons (Table 2). The lowest data coverage, between 29-61\%, was observed in 2006 and 
Table 2. Fraction of data coverage of the $\mathrm{CO}_{2}$ fluxes for each season and year separately.

\begin{tabular}{cccccc}
\hline & Winter & Spring & Summer & Fall & All \\
\hline 2006 & 0.29 & 0.36 & 0.51 & 0.43 & 0.41 \\
2007 & 0.50 & 0.54 & 0.47 & 0.61 & 0.53 \\
2008 & 0.60 & 0.67 & 0.73 & 0.62 & 0.68 \\
2009 & 0.63 & 0.58 & 0.71 & 0.75 & 0.68 \\
2010 & 0.52 & 0.59 & 0.65 & 0.78 & 0.62 \\
\hline
\end{tabular}

2007 when the open-path analyzer was used and malfunction during precipitation events was common. The best data coverage was in summer when $47-73 \%$ of data were present. In 2007 , the amount of missing summer data was higher due to the longer gap in data (39 days) caused by instrument malfunction.

Error analysis of the EC measurements was performed using data from 2009 and previously defined methods (Nordbo et al., 2012). The mean $\mathrm{CO}_{2}$ flux detection limit is $0.57 \mu \mathrm{mol} \mathrm{m}{ }^{-2} \mathrm{~s}^{-1}$ and $0.70 \mu \mathrm{mol} \mathrm{m}^{-2} \mathrm{~s}^{-1}$ for the closedand open-path analyzer, respectively. These correspond to $11 \%$ and $13 \%$ of the data and imply that the measurement setup is capable of detecting the flux level observed at the site. Furthermore, the random error was on average $16 \%$ and $18 \%$ of the closed- and open-path fluxes. These percentages lie within the range observed at vegetative sites (Finkelstein and Sims, 2001; Billesbach, 2011); similar urban studies are unavailable.

\subsubsection{Auxiliary measurements}

\section{Meteorology}

Wind speed and direction were calculated using data from the ultrasonic anemometer. In addition, photosynthetically active radiation (PAR) and air temperature were measured at $31 \mathrm{~m}$ in the measurement tower using a photodiode sensor (PAR Lite, Kipp\&Zonen, Delft, Netherlands) and a platinum resistance thermometer (Pt-100, home-made), respectively. These measurements were made with one minute time step. Relative humidity $(\mathrm{RH})$ and precipitation were measured on the roof of the University of Helsinki building with a thin film polymer sensor (HMP243, Vaisala Ltd., Vantaa, Finland) and a weighting rain gauge (Ott Pluvio, Ott Hydromet GmbH, Kempten, Germany), respectively, with a time step of four minutes. Gaps in wind speed, wind direction, air temperature and PAR data were filled using parallel measurements from other instruments from the SMEAR III station (Järvi et al., 2009a). For RH no parallel measurements existed and a three step gap filling procedure was used: (1) gaps less than an hour were filled with linear interpolation, (2) gaps less than one day were filled by calculating average value for each hour by using adjacent days and (3) for longer gaps averages from two days before and after the gap were used to calculate the averages.

\section{Road traffic}

Online traffic counts (Tr) with hourly resolution were measured by the city of Helsinki $4 \mathrm{~km}$ from the measurement site during the analyzed measurement period (Järvi et al., 2009a). Traffic count measurements with hourly resolution have also been carried out on the road next to the measurement station in 31 May-18 June 2006, 1422 November 2006 and 6-17 June 2007. These campaignwise traffic counts $\left(\operatorname{Tr}_{\text {Site }}\right)$ show a good correlation with the traffic counts monitored away from the measurement site $\left(\operatorname{Tr}_{\text {OffSite }}\right)$ with $\operatorname{Tr}_{\text {Site }}=0.94 \operatorname{Tr}_{\text {OffSite }}+49.3, R^{2}=0.76$, $\mathrm{RMSE}=381.3 \mathrm{veh} \mathrm{h}^{-1}(N=840)$. Traffic counts used in this study were converted for the road next to the measurement site using the linear relationship. Missing traffic counts were filled with a method depending on the gap length. Single missing hours were filled by using linear interpolation (all together three hours). Gaps less than one day (all together $531 \mathrm{~h}$ ) were filled by calculating the mean for each hour from the adjacent days. If either of the days was different type (weekday, weekend or holiday), that day was ignored in the calculation of the average. The longer gap in 11 May-4 August 2009 (2049h) was filled by calculating the median diurnal cycle for weekdays and weekends/holidays for each week from data from other years. In summer, traffic counts were similar between the years so this was considered to be a valid technique (Fig. 3a). In data analysis, traffic data were converted to half hour averages to match the resolution of $\mathrm{CO}_{2}$ fluxes.

\section{Soil respiration}

For soil respiration measurements we had two campaigns around the measurement tower in 2008 and 2009. The measurement setup used a Vaisala $\mathrm{CO}_{2}$ probe (GMP343, Vaisala Ltd., Vantaa, Finland) in the portable closed chamber $\mathrm{CO}_{2}$ measurement system described by Kolari et al. (2005). Soil respiration measurements were made in daytime. One measurement lasted $5 \mathrm{~min}$ and the $\mathrm{CO}_{2}$ concentrations were recorded every $5 \mathrm{~s}$. In both years we had the same measurement locations (three on a meadow, 11 in forest, four on lawns and 10 on cultivated land), which were measured several times during the campaigns. The number of measurement points was chosen according to the approximate surface cover fractions with extra points on the cultivated land due to possible fertilization. In 2008, the points were measured eight times between 26 June and 29 October, whereas in 2009, the points were measured 11 times between 28 May and 27 November. For both campaigns, median respiration values were calculated for each day by combining all locations. 


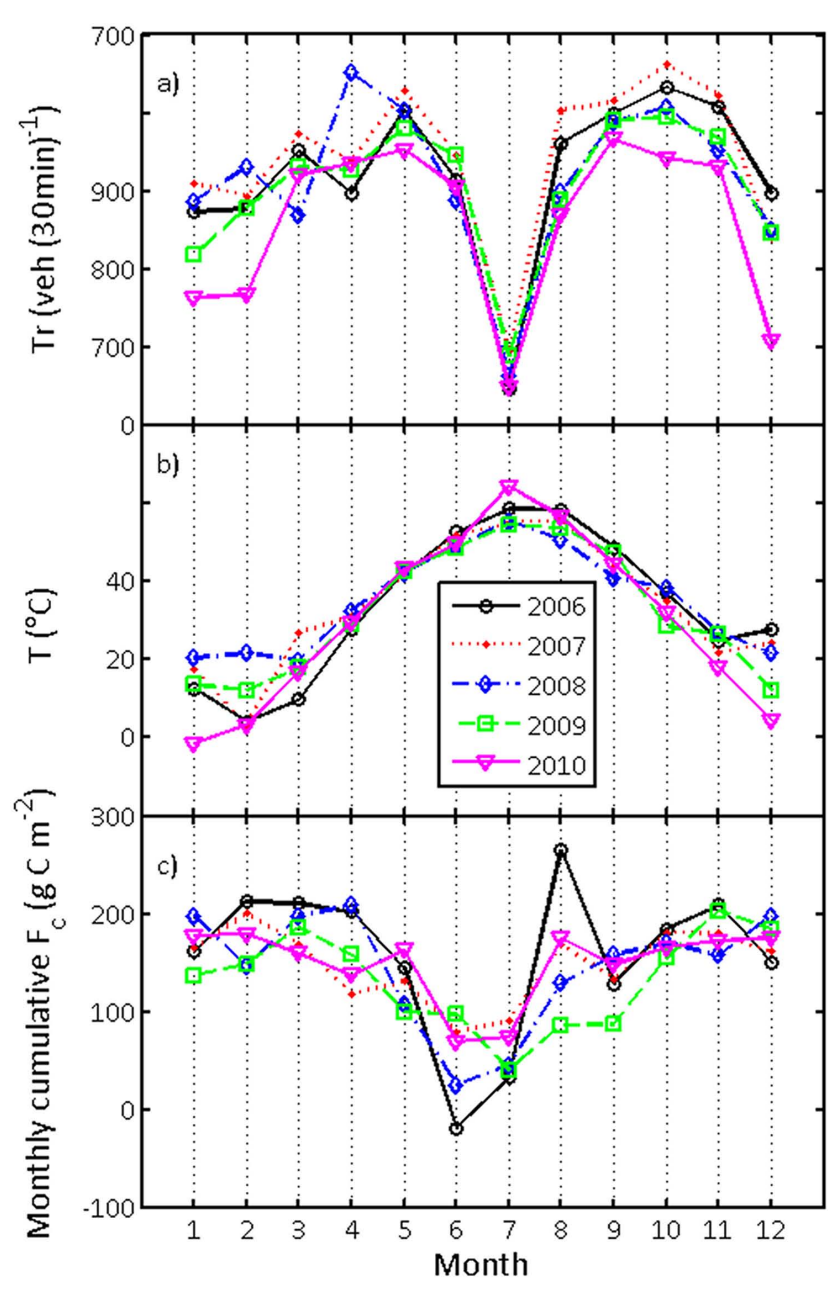

Fig. 3. Monthly mean (a) traffic rates and (b) air temperature, and (c) the monthly cumulative carbon flux separately for the studied years.

\subsection{Gap filling of the $\mathrm{CO}_{2}$ flux data}

We studied the effect of different methods to fill gaps in $\mathrm{CO}_{2}$ flux $\left(F_{c}\right)$ data. Firstly, we developed an artificial neural network (ANN, e.g. Jain et al., 1996) to fill the gaps. ANN is a powerful computational method that can be used to solve nonlinear relationships between set of input variables and an output variable or variables ( $F_{c}$ in this case). ANN has an ability of learning so that it can perform the specific task with aid of a sample dataset. Here, two different kinds of networks are developed: one having traffic counts as an input variable and another without traffic counts. This was done in order to examine the importance of traffic counts in gap filling since this information is not necessarily available at different sites. Secondly, we test how well the median diurnal cycles (MDC) of $F_{c}$ would fill the gaps.

\subsubsection{ANN}

In the gap filling of $F_{c}$ we use the multilayer perceptron network (MLP), which has previously been used to fill gaps in EC flux time series above vegetated surfaces (Papale and Valentini, 2003; Moffat et al., 2007). The same network has also been successfully used to fill gaps in air pollution concentration time series in urban areas (Junninen et al., 2004). MLP is a feed-forward network, where information is transmitted through memory units or neurons that are organized in layers. Before entering neurons in one layer, signals are weighted and in neurons the weighted input signals are summed and scaled using a transfer function before entering the signal to neurons in the next layer. In the beginning, values for the weights are randomly chosen and in the training process, the weights are adjusted using a back-propagation learning algorithm (for more information, see e.g. Jain et al., 1996). We used the Neural Network Toolbox of MATLAB ${ }^{\text {TM }}$ in the data analysis. Here, MLP is used though radial basis networks (RBS) has been shown to give better results in urban areas (Schmidt et al., 2008; Kordowski and Kuttler, 2010). MLP is more computationally efficient and therefore was used for our dataset.

Several different configurations for the network were tested with the basic idea that the network should be as simple as possible in order to avoid overfitting (random noise modeled as true fluxes). The most efficient network was obtained using the Levenberg-Marquardt algorithm in the learning process. We found that one hidden layer besides an input and output layer (altogether three layers) gave sufficient results and additional layers did not improve the performance of the network. In the hidden layer we used a logsigmoid transfer function to adjust the signal passing each node, whereas a linear transfer function was used in the output layer. We also tested what would be the sufficient number of input variables in both networks. Following Papale and Valentini (2003), variables present in each tested configuration were PAR, air temperature, and season and time of day. Season and time of day were treated as fuzzy variables: season was described using four fuzzy variables (winter, spring, summer and fall) each having a value between 0 and 1 depending on the time of year. Similarly, time of day was described using fuzzy variables night, morning, afternoon and day each having a value between 0 and 1 depending of the time of day. In addition, the surrounding area was divided into nine wind direction sectors $\left(0-40^{\circ}, 40-80^{\circ}, \ldots\right.$, $320-360^{\circ}$ ) according to the strong dependence between $F_{c}$ and wind direction (Figs. 1 and 4). Each of the sectors was presented as a binary input variable for MLP (WD1, WD2, ..., WD9), so that for each half hour only one of these wind direction variables would have a value one. Wind direction was not treated as a fuzzy variable since ANN will be used to generate artificial time series for the different wind direction sectors. In addition, RH and wind speed were included 

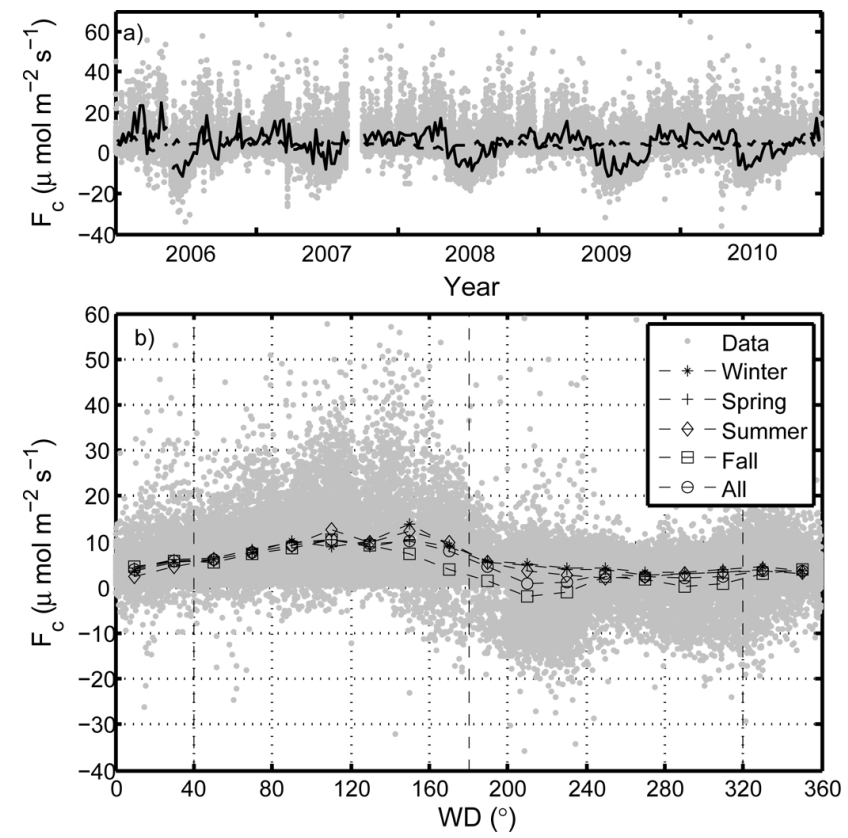

Fig. 4. (a) The measured half hour $\mathrm{CO}_{2}$ flux ( $F_{c}$, grey dots) and the 7-day averages calculated from daytime (10:00-14:00, solid line) and nocturnal (PAR $<5 \mu \mathrm{mol} \mathrm{m}{ }^{-2} \mathrm{~s}^{-1}$, dashed line) data, and (b) variation of $F_{c}$ as a function of wind direction. Besides 30-min averages (grey dots), the bin averaged fluxes $\left(20^{\circ}\right)$ for all data and separately for different seasons are plotted. The limits of built (320$\left.40^{\circ}\right)$, road $\left(40-180^{\circ}\right)$ and vegetation $\left(180-320^{\circ}\right)$ sectors are marked with dashed vertical lines.

among the meteorological variables to see if they improve the networks. All variables were scaled between 0 and 1 .

In the network development, half hour data points with all above mentioned input variables and $F_{c}$ available were used (accounting $54 \%$ of the data). Data points were not evenly distributed between the different seasons (winter $=$ 8637 , spring $=10003$, summer $=17229$, fall $=11179$ data points), which causes a bias to the learning of the network. Therefore, the same amount of data from each season was taken into the analysis with a total number of 34548 data points (covering $39 \%$ of the 5 -yr period). These data were arbitrarily divided into three parts: a third of the data was used to train the networks, a third for testing the networks and the final third was used for validating the networks.

The optimized number of neurons in the hidden layer was obtained by training the network repeatedly with varying number of neurons; multiple repetitions were needed in order to minimize the uncertainty rising from the randomly initialized network. Number of neurons varied from 3 to 15 , and 100 repetitions was thought to be sufficient. This was additionally repeated for both networks with and without traffic data. The performance of the network was measured using Root Mean Square Error (RMSE) that was divided into systematic and unsystematic part. The systematic RMSE $\left(\mathrm{RMSE}_{\mathrm{s}}\right.$ ) for the network including traffic counts and basic

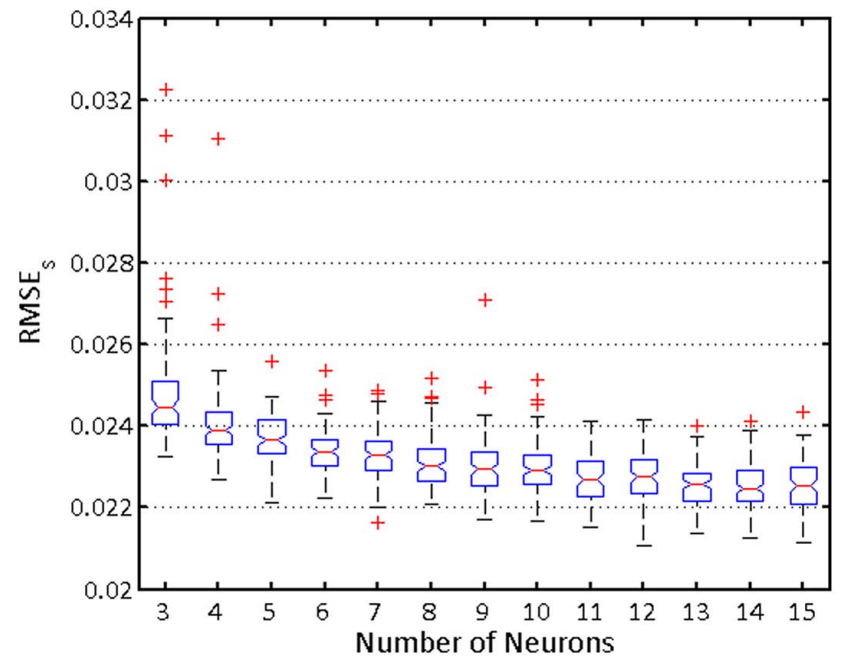

Fig. 5. Box plot of the systematic root mean square error $\left(\mathrm{RMSE}_{\mathrm{S}}\right)$ of the neural network (ANN $\mathrm{Araffic}_{\text {) }}$ calculated from 100 runs for each number of neurons in the hidden layer. The input variables for the model were traffic counts, PAR, air temperature, WD1-9, and four fuzzy variables to describe season and time of day, respectively.

variables listed above (all together 20 variables) is shown as box plots in Fig. 5. The performance of the network did not significantly (with $95 \%$ significance level) improve after five neurons and therefore the best network for this combination of input variables was 20-5-1 neurons in input, hidden and output layers, respectively (hereafter $\mathrm{ANN}_{\text {traffic }}$ ). Similarly the optimized network without traffic counts for the same basic variables was found to be 19-7-1 (hereafter $\mathrm{ANN}_{\text {notraffic }}$ ). The more complex network with seven neurons in the hidden layer, when traffic counts are excluded, is reasonable since one of the driving variables from the network is missing and more connections are needed. Neither network was significantly improved when RH and/or wind speed were included and therefore these variables were excluded.

\subsubsection{Median diurnal cycles (MDC)}

The same $2 / 3$ of the data used to train and test the artificial neural networks are used to calculate median diurnal cycles of $F_{c}$ for each type of day (weekdays and weekends/holidays), surface cover sector and season. This sums up to 24 different cycles. The surface cover areas: built, vegetation and road, are used instead of the $40^{\circ}$ sectors used in ANN due to the small number of data in each cycle.

\subsubsection{Error analysis}

To compare different gap filling methods, the biased errors (BE) are calculated using the validation dataset. Mean BE (in $\mu \mathrm{mol} \mathrm{m} \mathrm{m}^{-2} \mathrm{~s}^{-1}$ ) is calculated separately for the $40^{\circ}$ wind 
direction sectors from (Moffat et al., 2007).

$\mathrm{BE}_{\mathrm{wd}}=\frac{1}{N} \sum_{i=1}^{N}\left(\hat{y}_{i}-y_{i}\right)$,

where $N$ is the number of points in the independent dataset, $\hat{y}_{i}$ and $y_{i}$ are the modeled and observed $F_{c}$, respectively. Furthermore, the annual biased errors (AnnBE, in $\mathrm{g} \mathrm{C} \mathrm{m}^{-2}$ ) are calculated using

$\mathrm{AnnBE}=\sum_{\mathrm{wd}=1}^{9}\left(\mathrm{BE}_{\mathrm{wd}} \cdot N_{\mathrm{gap}, \mathrm{wd}} \cdot 1800 \mathrm{~s} \cdot M_{\mathrm{c}}\right)$,

where $N_{\text {gap, wd }}$ is the amount of missing half hour data points each year and $M_{\mathrm{c}}$ is the molar mass of carbon $\left(\mathrm{g} \mathrm{mol}^{-1}\right)$.

\subsection{Estimation of $\mathrm{CO}_{2}$ emissions from road traffic}

Road transport is major source for $\mathrm{CO}_{2}$ at our measurement site (Vesala et al., 2008) and therefore getting estimation for its source strength is important. The line source strength for $\mathrm{CO}_{2}$ at a distance $x$ from the measurement tower $(L(x))$ can be calculated from (e.g. Järvi et al., 2009c)

$L(x)=F_{c} F_{y}(x)^{-1}$,

where $F_{y}(x)$ is the cross-wind integrated footprint function value at a distance $x$ upwind from the measurement tower. Equation (3) was used to calculate $L(x)$ for wind directions $80-160^{\circ}$ (WD3 and WD4) in winter when the ground is covered with snow and biological activity is assumed to be minimal. The wind direction selection was done in order to minimize emissions from other sources including heating, vegetation and human respiration. In Helsinki, most of the buildings use district heating generated in power plants outside the footprint of our measurements. The only directions where some oil/wood combustion can take place in the source area of the measurements are the single-family house areas North and North-East from the tower. With good approximation this makes the chosen wind direction free from these emissions.

The cross-wind integrated footprint functions $F_{y}$ were calculated with the analytical footprint model by Kormann and Meixner (2001). We did not calculate $F_{y}$ for each half hour flux point but instead used look-up tables with a range of meteorological conditions. Depending on the prevailing wind direction, three surface roughness values representing built, road and vegetation areas were considered in the look-up tables. Wind speed was divided into 8 classes, standard deviation of the lateral wind speed into four classes and atmospheric stability into seven classes. Currently no generic footprint model for complex measurement sites exists and therefore the obtained footprints are only indicative for the impact of meteorological conditions rather than the actual source areas. Therefore calculated footprints were only used to approximate the source strength of the road, whereas division of data into different surface cover areas and sectors was made according to the prevailing wind direction.

\section{Results}

\subsection{Meteorology}

Figure 2 shows the annual behavior of daily averages of the gap filled meteorological variables. The high-latitude location is evident with both PAR and air temperature showing a strong annual cycle. In winter, little radiation and cold temperatures (minimum daily average $-20^{\circ} \mathrm{C}$ ) are observed, whereas in summer solar radiation is intense and daily air temperatures reach $26^{\circ} \mathrm{C}$. Also in winter the ground is typically covered with snow which melts during the spring. This strong seasonality and snow cover cause a relatively short growing season and fairly inactive vegetation in winter. $\mathrm{RH}$ reaches its maximum in winter and minimum in spring with daily averages varying between 30 and $98 \%$. Neither wind speed nor precipitation has strong annual dependence.

Naturally, there is also year-to-year variation in the meteorological conditions and in the length of seasons (Fig. 2). The winter 2007-2008 was exceptionally warm with daily air temperatures staying above zero in January-March, and the thermal season lasted only eight days. Snow cover was observed occasionally. In 2009-2010 Helsinki experienced the coldest and longest winter from the analyzed years (105 days, 138 days of snow) with a monthly mean temperature of $-11^{\circ} \mathrm{C}$ in January 2010 (Fig. 3b). Warm summers were observed in 2006 and 2010 with the summer 2006 being additionally dry and sunny. The warmest and also rainiest autumns were observed in 2006 and 2008 with a monthly rainfall of $170 \mathrm{~mm}$ and $200 \mathrm{~mm}$, respectively, in October.

\subsection{The $\mathrm{CO}_{2}$ exchange}

The behavior of $F_{c}$ during the measurement period is shown in Fig. 4a. Besides the 30-min data points, the 7day mean daytime (between 11:00-14:00) and nighttime $\left(\operatorname{PAR}<5 \mu \mathrm{mol} \mathrm{m}^{-2} \mathrm{~s}^{-1}\right.$ ) fluxes are plotted. The annual variation of $F_{c}$ is high with the 30-min values varying between -36 and $68 \mu \mathrm{mol} \mathrm{m} \mathrm{m}^{-2} \mathrm{~s}^{-1}$. The 7-day averages show clear downward fluxes reaching $-10 \mu \mathrm{mol} \mathrm{m}^{-2} \mathrm{~s}^{-1}$ in summer, whereas in winter the surroundings act as a source for $\mathrm{CO}_{2}$ with strength of $20 \mu \mathrm{mol} \mathrm{m}^{-2} \mathrm{~s}^{-1}$. Most of the downward fluxes in summer originate from the area of high fraction of vegetation cover (Fig. 2b). This direction is also the most commonly observed wind direction in Helsinki. The complex measurement surrounding creates a highly variable $F_{c}$ pattern with negative fluxes in direction $200-340^{\circ}$ and elevated emissions in direction $80-160^{\circ}$, where the road and large crossroads are located.

The median diurnal behavior of $F_{c}$ shows significant variations between the different surface cover areas and seasons (Fig. 6). The deviation into the surface cover areas was made according to the prevailing wind direction during each 30 -min period and not based on the modeled footprints of the flux. This is because source area estimation for such a 


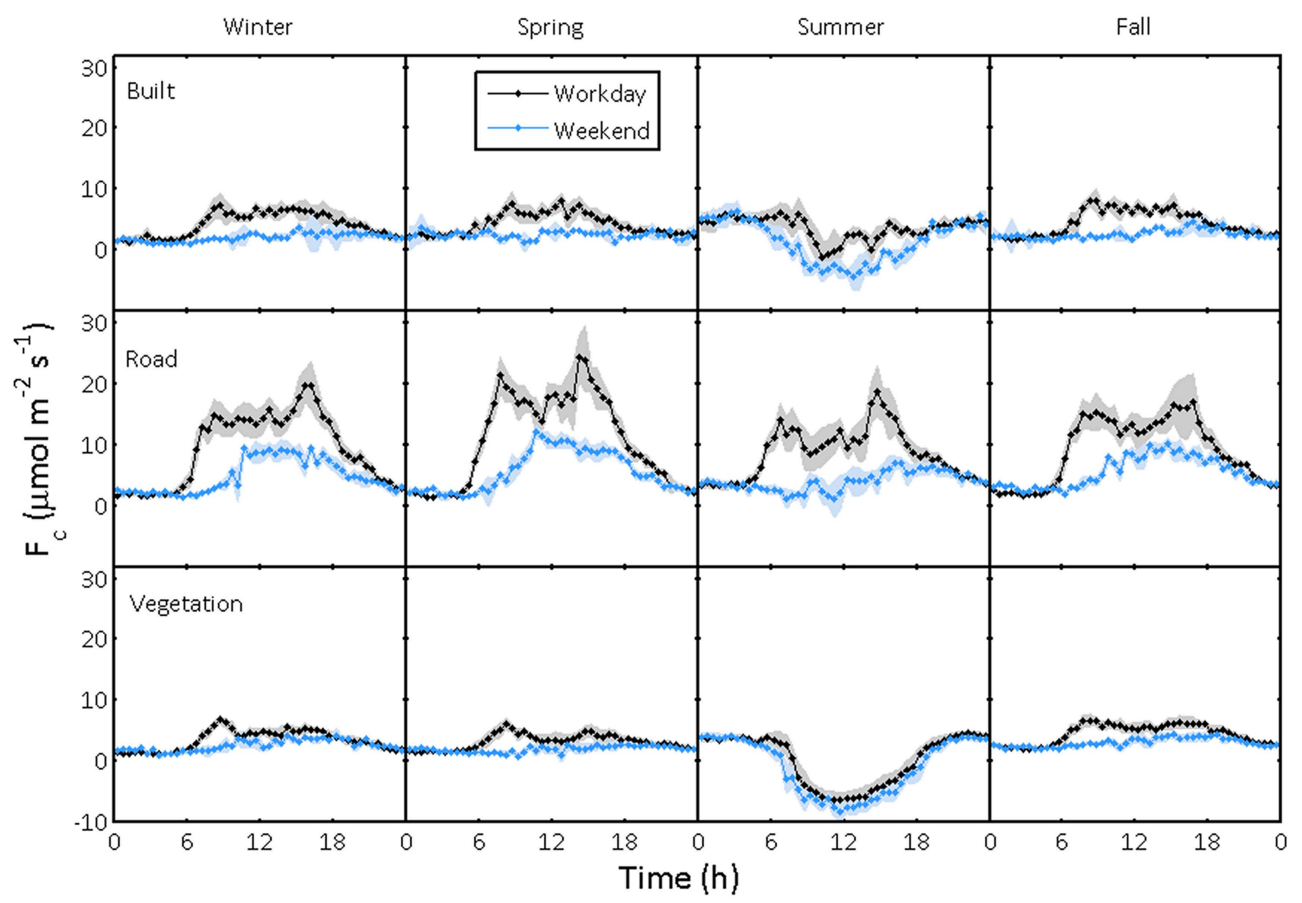

Fig. 6. Median diurnal variation of the $\mathrm{CO}_{2}$ flux $\left(F_{c}\right)$ for different surface cover areas in each thermal season. Separation to weekdays (black dotted line) and weekends/holidays (blue dotted line) was also made. Shadowed areas show the quartile deviations.

complex surrounding is only indicative and should be considered with caution. Through the year the highest fluxes are observed from the area of the road with maxima varying between 17 and $24 \mu \mathrm{mol} \mathrm{m}^{-2} \mathrm{~s}^{-1}$ on workdays, and between 7 and $12 \mu \mathrm{mol} \mathrm{m}{ }^{-2} \mathrm{~s}^{-1}$ on weekends/holidays. Both cycles follow the typical traffic patterns observed in Helsinki with two peaks corresponding to the rush hours on workdays, and the highest traffic rates between 10:00 and 14:00 on weekends. In winter, the morning peak at the direction of the road is not visible, which could be related to the shift of the footprint maxima further away from the road during the stable conditions before the sunrise. In summer, the fluxes are slightly lower and this is a combination of decreased traffic rates during the holiday season and increased carbon uptake by vegetation.

In the direction of both built and vegetation areas, the diurnal patterns outside summer are rather constant with workday maxima between $6.5-8.1 \mu \mathrm{mol} \mathrm{m}^{-2} \mathrm{~s}^{-1}$ and between 3$5 \mu \mathrm{mol} \mathrm{m}{ }^{-2} \mathrm{~s}^{-1}$ on weekends. In summer, the vegetation uptake has a clear effect on the measured net fluxes, particularly downwind from the vegetation area. The weekday and weekend cycles are similar with highest total uptakes of -7 and $-9 \mu \mathrm{mol} \mathrm{m} \mathrm{m}^{-2} \mathrm{~s}^{-1}$, respectively, indicating a small impact from anthropogenic activities. Similar daytime uptake $\left(-7 \mu \mathrm{mol} \mathrm{m}^{-2} \mathrm{~s}^{-1}\right)$ was observed at the suburban area in Montreal, where same fraction of vegetation cover is observed (Bergeron and Strachan, 2011). Stronger carbon sink has so far been observed in Baltimore where
$F_{c}$ of $-14 \mu \mathrm{mol} \mathrm{m}{ }^{-2} \mathrm{~s}^{-1}$ was measured in summer. In Essen similar division into surface types was used and a median sink of $5 \mu \mathrm{mol} \mathrm{m}{ }^{-2} \mathrm{~s}^{-1}$ was measured in a park, whereas in a built-up area an upward flux of $7 \mu \mathrm{mol} \mathrm{m}{ }^{-2} \mathrm{~s}^{-1}$ was observed. Through the year, the nocturnal fluxes are between 0.8 and $2.2 \mu \mathrm{mol} \mathrm{m}{ }^{-2} \mathrm{~s}^{-1}$ in all surface cover areas. These nocturnal fluxes are lower than those reported for the highly vegetated site in Baltimore, US, where a nocturnal flux of $4 \mu \mathrm{mol} \mathrm{m}{ }^{-2} \mathrm{~s}^{-1}$ was observed through the year. In both Montreal and London, nocturnal fluxes particularly during colder months are much higher than in our site and this is likely related to domestic heating of buildings. In general, reported values are similar to those given by Vesala et al. (2008) for a shorter measurement period for the same site.

\subsection{The effect of gap filling to the annual $\mathrm{CO}_{2}$ exchange}

The performances of the three gap filling methods described in Sect. 2.3 are tested for the validation dataset $(N=11516)$, and compared to the observed values. In addition, biased errors according to Eqs. (1) and (2) are compared.

The best correlation between the gap filled and measured $F_{c}$ is obtained when $\mathrm{ANN}_{\text {traffic }}$ is used (Fig. 7). For this RMSE is $3.9 \mu \mathrm{mol} \mathrm{m}^{-2} \mathrm{~s}^{-1}$, whereas for $\mathrm{ANN}_{\text {notraffic }}$ and MDC RMSE's are 4.5 and $4.4 \mu \mathrm{mol} \mathrm{m}{ }^{-2} \mathrm{~s}^{-1}$, respectively. Also the intercept for $\mathrm{ANN}_{\text {traffic }}$ is closer to zero than with the other two methods. All methods underestimate the highest emissions and overestimate downward fluxes, and $\mathrm{ANN}_{\text {traffic }}$ is the only method able to simulate as high as 


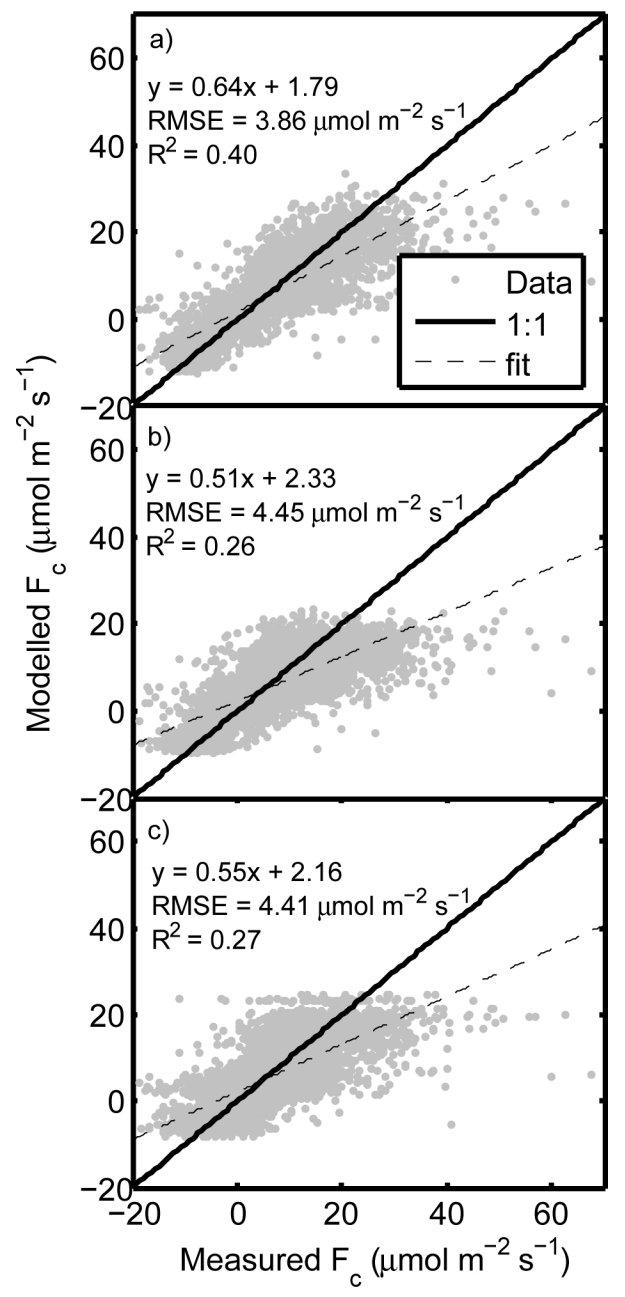

Fig. 7. The performance of the different gap filling methods for the independent dataset $(N=11516)$ : (a) is the ANN with traffic rates included, (b) the ANN without traffic rates and (c) the median diurnal cycle method.

$50 \mu \mathrm{mol} \mathrm{m} \mathrm{m}^{-2} \mathrm{~s}^{-1}$ fluxes. The inability of the methods to predict extreme values can be associated with unstationary situations that the recommended quality assurance routines cannot remove. The effect of different gap filling methods on annual carbon emissions is small and the average yearly emissions varies between 1740 and $1760 \mathrm{~g} \mathrm{C} \mathrm{m}^{-2}$ (Table 3). The annual biased errors are smallest for $\mathrm{ANN}_{\text {traffic }}$ with a slight over-estimation $\left(\mathrm{AnnBE}=6.1 \mathrm{~g} \mathrm{C} \mathrm{m}^{-2}\right)$ of the annual flux. The largest biased errors are related to the MDC with $\mathrm{AnnBE}=-20.5 \mathrm{~g} \mathrm{C} \mathrm{m}^{-2}$.

From the analyzed gap filling methods $\mathrm{ANN}_{\text {traffic }}$ generates the most reliable flux estimates, and therefore it will be used to fill gaps in the final $F_{c}$ series. The small differences between the methods on both half hourly and annual level show that reliable gap filling can be done without knowledge on the anthropogenic emission sources, but the biased error increases in this case. $\mathrm{ANN}_{\text {notraffic }}$ is able to learn the traf-

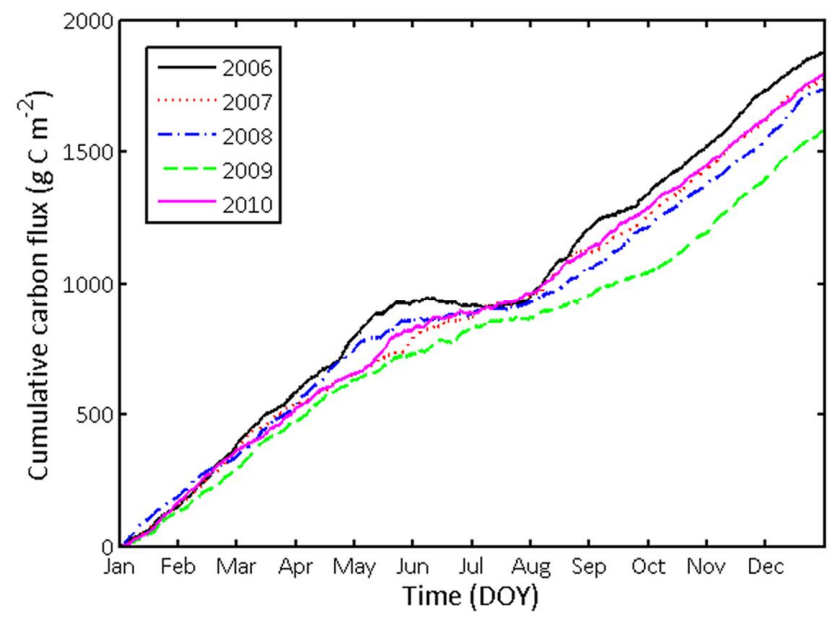

Fig. 8. Annual cumulative sums of $F_{c}$ (in $\mathrm{g} \mathrm{C} \mathrm{m}^{-2}$ ) for different years. Data was gap filled using $\mathrm{ANN}_{\text {traffic. }}$

fic related pattern from the diurnal cycle of other variables. Thus, ANN does not simulate the physical and biological processes itself and therefore the same network cannot directly be utilized at other sites. Small differences between different methods have also been observed above vegetated surfaces (Falge et al., 2001). Despite the small differences in AnnBE, systematization in gap filling methods between various urban areas should be made in order to get annual emissions more comparable.

\subsection{Annual $\mathrm{CO}_{2}$ emissions}

Figure 8 shows the cumulative carbon fluxes for the different years. Annually the source area of the measurements is a source for $\mathrm{CO}_{2}$ with average yearly emissions of $1760 \mathrm{~g} \mathrm{C} \mathrm{m}^{-2}$. The lowest annual emissions $1580 \mathrm{~g} \mathrm{C} \mathrm{m}^{-2}$ are observed in 2009 when $16 \%$ less $\mathrm{CO}_{2}$ was emitted to the atmosphere than in 2006, when annual emissions of $1880 \mathrm{~g} \mathrm{C} \mathrm{m}^{-2}$ are observed. The lower annual value in 2009 is mainly a result of lowered emissions in August-September (Fig. 3c). The dominant wind direction in Aug-Sep 2009 is from the vegetation area with an occurrence of $70 \%$, whereas on other years the occurrence from the same direction is $50 \%$. Therefore, the lower emissions in 2009 are rather related to synoptic conditions and the complex measurement surrounding than to lowered emissions and increased sinks.

Annual emissions from the urban site are around eight times higher than the average annual uptake of carbon $\left(-209 \mathrm{~g} \mathrm{C} \mathrm{m}^{-2}\right)$ observed in a boreal forest in Southern Finland (Kolari et al., 2009). Similarly, the yearly emissions are 40 times the annual sink $\left(-43 \mathrm{~g} \mathrm{C} \mathrm{m}^{-2}\right)$ of a Finnish wetland (Rinne et al., 2007). When compared to other urban areas, the annual emissions from Helsinki are at the lowest end of the reported values (Table 4). Similar emissions with $1420 \mathrm{~g} \mathrm{C} \mathrm{m}^{-2}$ have been measured from the suburban site in Montreal, where the fraction of vegetation is 
Table 3. The annual $\mathrm{CO}_{2}$ fluxes (in $\mathrm{g} \mathrm{C} \mathrm{m}^{-2}$ ) and biased errors (AnnBE, Eq. 2) with different gap filling methods: artificial neural network with and without traffic counts $\left(\mathrm{ANN}_{\text {traffic }}\right.$ and $\mathrm{ANN}_{\text {notraffic }}$, respectively) and median diurnal cycles (MDC). For $\mathrm{ANN}$ traffic , annual emissions are also given separately for the road and vegetation surface areas.

\begin{tabular}{|c|c|c|c|c|c|c|c|c|c|c|}
\hline & \multicolumn{10}{|c|}{ Annual $F_{c}\left(\mathrm{~g} \mathrm{C} \mathrm{m}^{-2}\right)$} \\
\hline & \multicolumn{6}{|c|}{$\mathrm{ANN}_{\text {traffic }}$} & \multicolumn{2}{|c|}{$\mathrm{ANN}_{\text {notraffic }}$} & \multicolumn{2}{|c|}{ MDC } \\
\hline & All & AnnBE & Road & AnnBE & Veg & AnnBE & All & AnnBE & All & AnnBE \\
\hline 2006 & 1880 & 8 & 3620 & 170 & 870 & -14 & 1840 & -13.3 & 1840 & -30.4 \\
\hline 2007 & 1780 & 3 & 3620 & 170 & 890 & -14 & 1770 & -10.2 & 1710 & -24.7 \\
\hline 2008 & 1740 & 5 & 3490 & 170 & 890 & -13 & 1760 & -7.1 & 1740 & -14.3 \\
\hline 2009 & 1580 & 8 & 3460 & 170 & 850 & -13 & 1620 & -6.9 & 1590 & -20.0 \\
\hline 2010 & 1800 & 7 & 3340 & 170 & 860 & -14 & 1830 & -7.8 & 1800 & -13.2 \\
\hline Average & 1760 & 6 & 3500 & 167 & 870 & -14 & 1760 & -9.1 & 1740 & -20.5 \\
\hline
\end{tabular}

Table 4. Annual $\mathrm{CO}_{2}$ emissions (NEE, $\mathrm{g} \mathrm{C} \mathrm{m}^{-2}$ ) observed in urban studies and the methods used to obtain them. Only studies where more than 12 months have been reported are listed. Also the plan area fractions of vegetation $\left(f_{\mathrm{veg}}\right)$ are given.

\begin{tabular}{lllll}
\hline City & Observation period & $\begin{array}{l}\text { NEE } \\
\left(\mathrm{g} \mathrm{C} \mathrm{m}^{-2}\right)\end{array}$ & Gap filling method & $f_{\text {veg }}$ \\
\hline This study & Jan 2006-Dec 2010 & 1760 & ANN & 0.44 \\
Essen $^{1}$ & Sep 2006-Oct 2007 & 3940 & ANN & 0.22 \\
London $^{2}$ & Oct 2006-May 2008 & 9690 & Daily averages & 0.08 \\
Baltimore $^{3}$ & Jan 2002-Dec 2006 & 361 & PAR in daytime, $T_{\text {soil in night-time }}$ & 0.67 \\
Vancouver $^{4}$ & May 2008-Apr 2010 & 6710 & Median diurnal cycles & 0.34 \\
Montreal-urb $^{5}$ & Nov 2007-Oct 2009 & 5570 & From average daily $F_{C}+$ interpolation & 0.29 \\
Montreal-sub $^{5}$ & Nov 2007-Oct 2009 & 1420 & From average daily $F_{C}+$ interpolation & 0.50 \\
Tokyo $^{6}$ & May 2001-Apr 2002 & 3350 & Look-up tables & 0.21 \\
Melbourne $^{7}$ & Feb 2004-Jun 2005 & 2320 & GRNN & 0.37 \\
Beijing $^{8}$ & Jan 2006-Dec 2009 & 4860 & Gap length dependent: interpolation, & 0.15 \\
& & & mean diurnal cycle, multiple imputation method
\end{tabular}

\footnotetext{
${ }^{1}$ Kordowski and Kuttler (2010), ${ }^{2}$ Helfter et al. (2010), ${ }^{3}$ Crawford et al. (2011), ${ }^{4}$ Christen et al. (2011), ${ }^{5}$ Bergeron and Strachan (2011),

${ }^{6}$ Moriwaki and Kanda (2004), ${ }^{7}$ Coutts et al. (2007), ${ }^{8}$ Liu et al. (2012)
}

also $50 \%$ (Bergeron and Strachan, 2011). So far the lowest emissions have been reported from the highly vegetated site in Baltimore, US, where a value of $361 \mathrm{~g} \mathrm{C} \mathrm{m}^{-2}$ was observed (Crawford et al., 2011). The highest annual emissions of $9670 \mathrm{~g} \mathrm{C} \mathrm{m}^{-2}$ have been observed in a city scale in London (Helftner et al., 2011). However, used gap filling methods are highly variable between the different studies and none of them, excluding the current one, gives error estimates for their annual emissions (Table 4). In addition, in most studies the annual estimates are based on 24 or less months and representativeness of the measurement periods are not clear as information about the year-to-year variations are not available. Therefore, direct comparisons between the different studies should be made with caution.

ANN can be used to examine separately the annual carbon balances at different wind directions around the measurement tower. If we use the meteorological input data and set one of the wind direction inputs to one (equals to an as- suming that wind was from that particular sector during the whole measurement time), we can predict $F_{c}$ for this certain wind direction using measured meteorological conditions. $F_{c}$ was predicted for sectors WD3 $\left(80-120^{\circ}\right)$ and WD6 $\left(200-240^{\circ}\right)$ representing the road and vegetation areas, respectively. These sectors are in the middle of the surface areas so they can be assumed to be representative of them. The cumulative sums obtained for these two surface areas differ largely (by $75 \%$ ) and annually the road area emits on average 3500 (170) $\mathrm{g} \mathrm{C} \mathrm{m}^{-2}$, whereas from the vegetation area the annual emissions are on average 870 (10) $\mathrm{g} \mathrm{C} \mathrm{m}^{-2}$. The errors represent AnnBE. Despite the strong carbon sink in the vegetation area in summer (Fig. 6), annually the area is as a net source for $\mathrm{CO}_{2}$. In Montreal (Bergeron and Strachan, 2011), a difference of $4150 \mathrm{~g} \mathrm{C} \mathrm{m}^{-2}$ was observed between urban and suburban measurement sites (Table 4). The results show that the upwind surface area affects strongly the annual $\mathrm{CO}_{2}$ emissions and in order to get a representative values in 


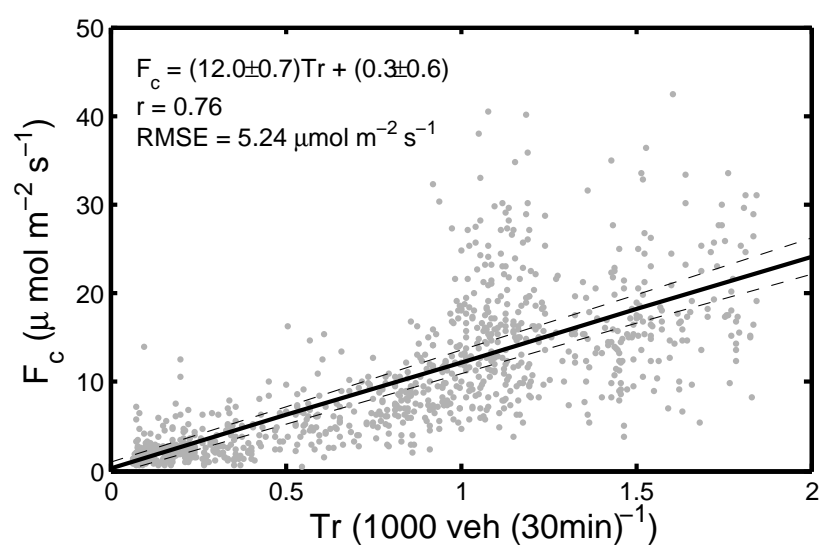

Fig. 9. $\mathrm{CO}_{2}$ exchange as a function of traffic rate for winter time when ground was covered with snow. The black line shows the linear fit to the data points and dashed lines the error limits for the fit.

a city scale, measurements covering different surface cover types are needed.

Time series for separate surface cover areas allow us to study how annual emissions from the different surface cover types have varied during the studied years and what reasons might be behind the observed differences. This removes the problem of varying wind direction as discussed above. In the area of the road, the predicted emissions decreased $8 \%$ between 2006 and 2010 (Table 3). At the same time the traffic rates have increased suggesting the decrease to be caused by reduced $\mathrm{CO}_{2}$ emissions from individual vehicles (see also Sect. 3.5). Particularly low emissions are observed during winter months in 2010 (not shown), when the weather was cold resulting in decreased vehicle numbers. On the other hand, particularly high $F_{c}$ is observed in August 2006 and 2007 following the higher traffic rates. Decreasing trend between the years is not observed in the area of high fraction of vegetation cover, where annual emissions varied $4 \%$ between the years. On monthly level, the strongest sink of $90 \mathrm{~g} \mathrm{C} \mathrm{m}^{-2}$ is observed in June 2006 whereas the sink is only $60 \mathrm{~g} \mathrm{C} \mathrm{m}^{-2}$ in 2008 (not shown). The strong sink in summer 2006 was observed in all wind directions and this was caused by the exceptionally warm and sunny weather observed in whole Europe. This shows how long-term measurements of $F_{c}$ are needed in order to distinguish the effect of exceptional weather condition on carbon fluxes.

\subsection{Road traffic $\mathrm{CO}_{2}$ emissions}

Figure 9 shows the $\mathrm{CO}_{2}$ exchange as a function of traffic counts for winter when the ground was covered with snow and wind was from 80-120 ${ }^{\circ}$ (WD3). $F_{c}$ can be related to hourly traffic rate using a linear fit $F_{y}=(12.0 \pm 0.7) \mu \mathrm{mol} \mathrm{m}{ }^{-2} \mathrm{~s}^{-1}(30 \mathrm{~min}) \mathrm{veh}^{-1} \mathrm{Tr}+$ $(0.26 \pm 0.64) \mu \mathrm{mol} \mathrm{m}^{-2} \mathrm{~s}^{-1} \quad\left(\mathrm{RMSE}=5.2 \mu \mathrm{mol} \mathrm{m}^{-2} \mathrm{~s}^{-1}\right.$, $r=0.76)$. In some studies, the fit between traffic counts and $F_{c}$ has been approximated with an exponential fit (Helfter et al., 2011), but in our case the linear fit seems reasonable $(p<0.001)$. The intercept can be considered to represent emissions from other sources than traffic and for this specific case we see that other emissions are insignificant. If the same fit is assumed to be valid through the year, we can estimate annual carbon emissions using the gap filled traffic counts. On average, this results in annual emissions of $3520 \mathrm{~g} \mathrm{C} \mathrm{m}^{-2}$. Following the observed behavior in the previous section, lowest emissions from traffic are observed in 2010. On annual level, other sources and sinks in the direction of the road seem to cancel each other out since emissions caused by the road traffic are almost equal to the net $\mathrm{CO}_{2}$ exchange $3500 \mathrm{~g} \mathrm{C} \mathrm{m}^{-2}$ (Table 3 ). However, as the annual $\mathrm{CO}_{2}$ emissions from traffic are based on winter time fit, the results should be considered with caution. Unfortunately, a detailed division into different components (vegetation and soil respiration, vegetation uptake) was not possible.

The line source strength $L(x)$ per vehicle gives estimation for a mixed fleet emission factor (Järvi et al., 2009c). The mean distance $x$ to the road is $160 \mathrm{~m}$ when the wind is from $80-100^{\circ}$ and $150 \mathrm{~m}$ when wind is from $100-120^{\circ}$. This yields an emission factor of $380 \mathrm{~g} \mathrm{~km}^{-1}$ with a quartile deviation of $110 \mathrm{~g} \mathrm{~km}^{-1}$ for $\mathrm{CO}_{2}(N=589)$. We can estimate the mixed fleet emission factor also from fuel consumption if we know the typical traffic distribution and emission factors for different type of cars at the road passing the measurement site. Typical emission factors in city driving in Finland are: for passenger cars $200 \mathrm{~g} \mathrm{~km}^{-1}$, city buses $1240 \mathrm{~g} \mathrm{~km}^{-1}$, vans $280 \mathrm{~g} \mathrm{~km}^{-1}$ and trucks $1500 \mathrm{~g} \mathrm{~km}^{-1}$ (VTT, 2010). From the typical traffic distribution in Helsinki (83\% passenger cars, $10 \%$ vans, $3 \%$ trucks and $4 \%$ buses; Lilleberg and Hellman, 2011), we can estimate the mixed fleet emission factor to be $285 \mathrm{~g} \mathrm{~km}^{-1}$. This is lower but in the same order of magnitude as the one calculated from the EC measurements. The correspondence between the two values is surprisingly good if the possible error sources of both estimations, and that the emission factor from EC is only from winter time, are taken into account. For the measured value, the largest uncertainty are likely related to the cross-wind integrated footprint value, and for the one based on the fuel consumption, error sources include the estimation of the typical value for each vehicle type and the traffic distribution. Also cars next to our measurement site can spend lot of time in traffic lights which would increase the emission factors. If we compare the emission factors between the years, the emission factors were higher in 2006 and 2007 than in 2009 and 2010 (from $502 \mathrm{~g} \mathrm{~km}^{-1}$ in 2006 to $361 \mathrm{~g} \mathrm{~km}^{-1}$ in 2010). This is an indicator for changes in fuel content and age structure of the vehicles as has been reported to take place in Finland by Ministry of Transport and Communications (Jääskeläinen, 2011). On the other hand, in November 2008 one of the main harbors was moved from the centre of Helsinki to east decreasing the 

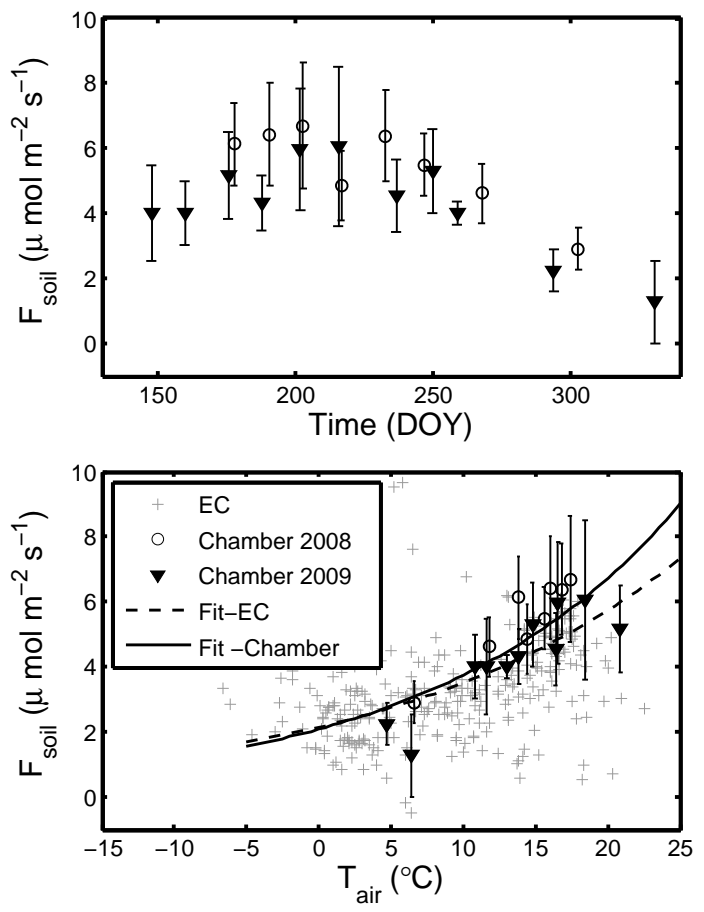

Fig. 10. (a) Soil chamber respiration $\left(F_{\text {soil }}\right)$ as a function of time, and (b) the dependence of $F_{\text {soil }}$ on daily air temperature $\left(T_{\text {air }}\right)$ in 2008 and 2009 (circles and triangles, respectively). In (b) the fit $F_{\text {soil }}=2.1 \pm 0.8 e^{\left(0.06 \pm 0.03 T_{\text {air }}\right)}\left(\mathrm{RMSE}=0.9 \mu \mathrm{mol} \mathrm{m}{ }^{-2} \mathrm{~s}^{-1}\right.$, $\left.R^{2}=0.65\right)$ is shown with a black line and the nocturnal fluxes ( $\mathrm{PAR}<5 \mu \mathrm{mol} \mathrm{m}{ }^{-2} \mathrm{~s}^{-1}$ ) measured with the EC technique from wind direction $200-240^{\circ}$ are shown with grey crosses and fit $F_{\mathrm{EC}}=(2.1 \pm 1.7) e^{\left(0.05 \pm 0.05 T_{\text {air }}\right)}\left(\mathrm{RMSE}=1.0 \mu \mathrm{mol} \mathrm{m}{ }^{-2} \mathrm{~s}^{-1}\right.$, $\left.R^{2}=0.32\right)$ with a black dashed line.

number of trucks by $0.8 \%$ from the Helsinki centre (Lilleberg and Hellman, 2011).

\subsection{Soil respiration}

The soil respiration $\left(F_{\text {soil }}\right)$ measured with the chamber exhibits a clear seasonal dependence as shown in Fig. 10a, where the median $F_{\text {soil }}$ and its quartile deviations calculated over the different measurement spots are shown. The median flux reaches its maximum $6.7 \mu \mathrm{mol} \mathrm{m}^{-2} \mathrm{~s}^{-1}$ at the end of July, and minimum (less than $2 \mu \mathrm{mol} \mathrm{m}^{-2} \mathrm{~s}^{-1}$ ) at the end of October-beginning of November. Note, however, that we did not have winter time chamber measurements. Soil respiration increases with increasing air temperature following an exponential relationship $F_{\text {soil }}=(2.1 \pm 0.8) e^{\left(0.06 \pm 0.03 T_{\text {air }}\right)}$ $\left(\mathrm{RMSE}=0.9 \mu \mathrm{mol} \mathrm{m}^{-2} \mathrm{~s}^{-1}, R^{2}=0.65\right) \quad$ (Fig. 10b). The nocturnal EC fluxes for wind directions $200-240^{\circ}$ (WD6) for the same time period as the chamber measurements were made are shown in Fig. 10b. An exponential fit yields $F_{\mathrm{EC}}=$ $(2.1 \pm 1.7) e^{\left(0.05 \pm 0.05 T_{\text {air }}\right)}\left(\right.$ RMSE $=1.0 \mu \mathrm{mol} \mathrm{m}^{-2} \mathrm{~s}^{-1}, R^{2}=$ 0.32). Agreement between the two measurement techniques is surprising and EC gives only slightly smaller values than chambers due to e.g. different representativeness of soil types in chamber measurements and at the EC footprint. Generally EC method has been found to measure lower $F_{c}$ than chambers (Goulden et al., 1996; Launiainen et al., 2005). Both estimations give similar temperature response, although chamber measurements were done during daytime, when surface soil temperatures tend to be higher than in night-time. The fit between $F_{\text {soil }}$ and daily $T_{\text {air }}$ is used to calculate daily soil respiration over the whole year resulting in annual emissions of $1100 \mathrm{~g} \mathrm{C} \mathrm{m}^{-2}$ and $1290 \mathrm{~g} \mathrm{C} \mathrm{m}^{-2}$ in 2008 and 2009 , respectively. Here the fit was only applied to above zero temperatures and below zero respiration was assumed to be negligible. If we take into account that about $50 \%$ of the surface in WD6 (and in the vegetation surface area in general) is covered with vegetation and assume that the whole surface emits with the same strength, we get $550 \mathrm{~g} \mathrm{C} \mathrm{m}^{-2}$ and $645 \mathrm{~g} \mathrm{C} \mathrm{m}^{-2}$ in 2008 and 2009 for the net effect of soil respiration. Thus, as a rough estimate soil respiration can be estimated to account $63 \%$ of the annual carbon emissions from the area. The rest $37 \%$ is a combination of other $\mathrm{CO}_{2}$ sources in the area minus carbon uptake by vegetation.

The values in this study are higher than the modeled soil respiration rates in Vancouver, Canada, where the annual soil respiration was estimated to be $280 \mathrm{~g} \mathrm{C} \mathrm{m}^{-2}$ (Christen et al., 2011). In addition to the different methods used to estimate soil respiration, the large difference between the two studies can be caused by different vegetation in the study areas, and litter quantity and quality, as in Vancouver the ground is covered by lawns while in our study area vegetation is highly variable, from broadleaf forest to kitchen gardens.

\subsection{Environmental controllers}

The key variables controlling $\mathrm{CO}_{2}$ exchange in the study area are the anthropogenic emission, PAR and air temperature. To get information about their seasonal effect on carbon fluxes, correlation coefficients $(r)$ between $F_{c}$ and each variable were calculated from daily averages in a 30-day moving window for the whole 5-yr of measurements. Before the calculation of $r$, all time series were normalized between -1 and 1. Figure 11 shows the nocturnal and daytime correlation coefficients separately for each surface cover area. In the urban and vegetation areas, the daytime summer $F_{c}$ are controlled by PAR with $r$ reaching -0.8 (Fig. 11a, c). With increasing radiation, the carbon uptake increases causing higher negative fluxes. In winter, both the nocturnal and daytime fluxes are largely determined by the road traffic. Downwind from the road, $F_{c}$ correlates best with traffic rates through the year with slightly decreasing correlation in summer when the vegetation is most active. However, unlike in other surface cover areas, road traffic remained as the most important factor controlling the exchange of $\mathrm{CO}_{2}$. In all surface cover areas, road traffic explains the nocturnal fluxes most except in summer when the soil and vegetation respiration decreases the importance of road traffic. 


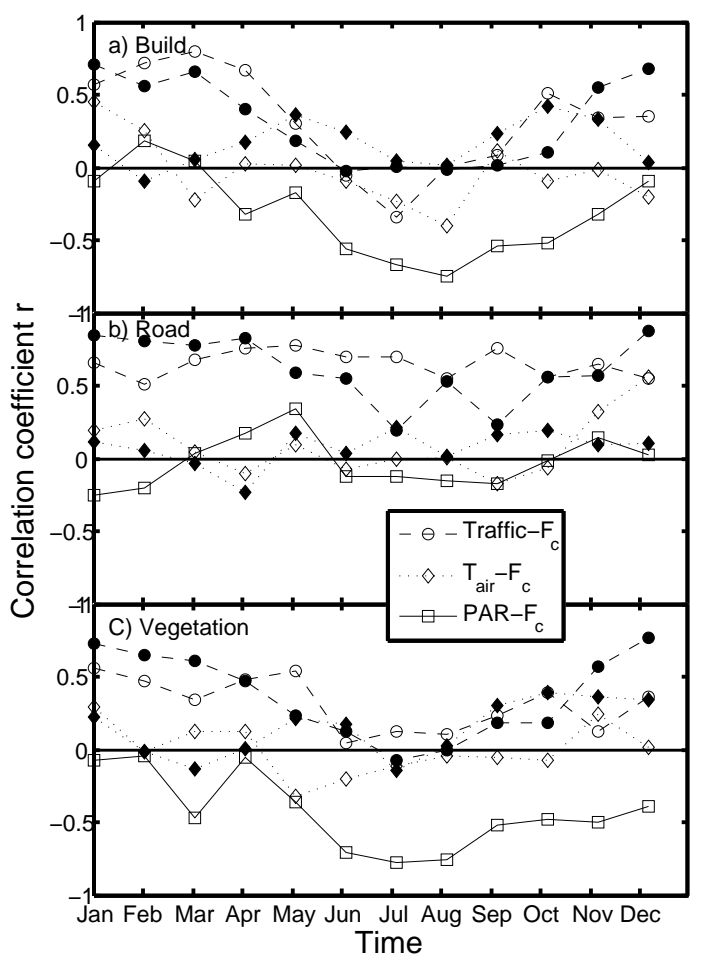

Fig. 11. Temporal variation of the correlation coefficient $(r)$ between $F_{c}$ and its environmental drivers: road traffic, air temperature $\left(T_{\text {air }}\right)$ and PAR, for (a) built, (b) road and (c) vegetation surface areas. Open markers are daytime and closed markers night-time correlation coefficients.

In a Finnish boreal forest, air temperature has been found to be the dominant factor explaining gross primary product (GPP) in spring but as the growing season progresses the stand photosynthesis is increasingly determined by radiation (Vesala et al., 2010). At our urban site, air temperature has smaller correlations coefficients than PAR in daytime, but slightly increased correlation between air temperature and $F_{c}$ is seen in March-April downwind from the vegetation area (Fig. 11c). In boreal forests, soil temperature has been found to have highest correlation coefficients with soil respiration particularly in May and September-November (Vesala et al., 2010). Unfortunately we did not have continuous soil temperature measurements, but nocturnal $F_{c}$ correlated with daily air temperature, and the nocturnal $F_{c}$ showed maxima in May-June and September-November in the area of high fraction of vegetation cover, similarly to the forest. Similar correlation coefficient analysis has not been made in urban areas before, so comparisons between other urban studies cannot be made.

\section{Conclusions}

In this study we examined five years of $\mathrm{CO}_{2}$ exchange measurements carried out with the eddy covariance technique in
Helsinki, Finland. The measurements were made at the urban measurement station SMEAR III in 2006-2010. It is the northernmost urban flux station and, therefore, provided surroundings to examine the seasonal and interannual variation of the $\mathrm{CO}_{2}$ exchange. Furthermore, the advantage of the station is that the surrounding area is heterogeneous and three different surface cover areas can be distinguished and evaluated separately. Additionally, three different methods to fill gaps in the $\mathrm{CO}_{2}$ flux time series were tested. These were (i) artificial neural network including measured traffic counts as an input variable and (ii) a network using only meteorological variables as an input, and (iii) look-up tables using median diurnal cycles.

The measured fluxes were highly dependent on the prevailing wind direction with the highest observed fluxes in the direction of large road and crossroads on workdays, and lower ones $\left(-9 \mu \mathrm{mol} \mathrm{m}^{-2} \mathrm{~s}^{-1}\right)$ in the vegetation area both on weekdays and weekends. In the road area, the annual emissions caused by road traffic were on average $3520 \mathrm{~g} \mathrm{C} \mathrm{m}^{-2}$. The other $\mathrm{CO}_{2}$ sources and carbon uptake cancelled each other on an annual level since the emissions from traffic were almost the same as the net $\mathrm{CO}_{2}$ emissions $3500 \mathrm{~g} \mathrm{C} \mathrm{m}^{-2}$. Despite the strong sink on summer days, the area with high fraction of vegetation cover remained as a source for $\mathrm{CO}_{2}$ with average annual emissions of $870 \mathrm{~g} \mathrm{C} \mathrm{m}^{-2}$. The wind direction affected also the seasonal variation of the measured fluxes. In the road area, deviations between seasons were small and were more related to the reduced traffic rates during the holiday rather than vegetation activity. In the built and vegetation areas, the seasonal variations were stronger and the effect of vegetation uptake was clear in daytime in summer. In these areas $\mathrm{CO}_{2}$ exchange was determined by road traffic in winter whereas in summer PAR and air temperature became more important.

All gap filling methods underestimated the highest and lowest fluxes, but differences between the methods were small. Slightly better results were obtained when an artificial neural network with traffic counts as one of the input variable was used. Thus, successful gap filling can also be made without information of the exact traffic counts. The best gap filling gave a cumulative sum of $1760 \mathrm{~g} \mathrm{C} \mathrm{m}^{-2}$ for the overall source area with a standard error of $6 \mathrm{~g} \mathrm{C} \mathrm{m}^{-2}$ caused by the gap filling. Despite the small differences in annual biased errors, systematization in gap filling methods between various urban areas should be made. Variations in the annual emissions between different years were small and the lowest emission $1580 \mathrm{~g} \mathrm{C} \mathrm{m}^{-2}$ was observed in 2009. This was due to the prevailing wind direction which was most of the time $(70 \%)$ downwind from the area of high vegetation cover fraction. Unfortunately, detailed division of the annual exchanges to different components was not possible. Emission factors calculated for mixed fleet traffic from the flux measurements were in the same order of magnitude as the ones obtained from emission inventories. 
The large variability of the annual emissions in different surface cover areas shows that in order to get realistic emission values for cities, measurement covering various surface types are needed. Developed ANN can be utilized on modeling hypothetical case studies where for example traffic intensities are increased or vegetation areas are replaced by traffic or built areas. This would be a valuable tool for city planning. Also in future more attention should be given to the calculation of annual estimations of $\mathrm{CO}_{2}$ if these are used in emission inventories in global and regional models.

Acknowledgements. This work was supported by the Academy of Finland (Project numbers 138328, 1118615 and ICOS-Finland, 263149), Nessling foundation and public works department of City of Helsinki, and EU-funded projects BRIDGE, IMECC, ICOS and GHG-Europe. We also acknowledge Erkki Siivola and Petri Keronen for taking care of the measurement setup along the years.

Edited by: M. Heimann

\section{References}

Baldocchi, D. D.: Assessing the eddy covariance tehcnique for evaluating carbon dioxide exchange rates of ecosystems: past, present and future, Glob. Change Biol., 9, 479-492, 2003.

Bergeron, O. and Strachan, I. B.: $\mathrm{CO}_{2}$ sources and sinks in urban and suburban areas of a northern mid-latitude city, Atmos. Environ., 45, 1564-1573, 2011.

Billesbach, D. P.: Estimating uncertainties in individual eddy covariance flux measurements: A comparison of methods and a proposed new method, Agr. Forest Meteorol., 151, 394-405, 2011.

Burba, G. G., McDermitt, D. K., Grelle, A., Anderson, D. J., and $\mathrm{Xu}, \mathrm{L}$.: Addressing the influence of instrument surface heat exchange on the measurements of $\mathrm{CO}_{2}$ flux from open-path gas analyzers, Glob. Change Biol., 14, 1-23, 2008.

Christen, A., Coops, N. C., Crawford, B. R., Kellett, R., Liss, K. N., Olchovski, I., Tooke, T. R., van der Laan, M., and Voogt, J. A.: Validation of modeled carbon-dioxide emissions from an urban neighborhood with direct eddy-covariance measurements, Atmos. Environ., 45, 6057-6069, 2011.

Coutts, A. M., Beringer, J., and Tapper, N.: Characteristics influencing the variability of urban $\mathrm{CO}_{2}$ fluxes in Melbourne, Australia, Atmos. Environ., 41, 51-62, 2007.

Crawford, B., Grimmond, C. S. B., and Christen, A.: Five years of carbon dioxide fluxes measurements in a highly vegetated suburban area, Atmos. Env., 45, 896-905, 2011.

Falge, E., Baldocchi, D., Olson, R., Anthoni, P., Aubinet, M., Bernhofer, C., Burba, G., Ceulemans, R., Clement, R., Dolman, H., Granier, A., Gross, P., Grünwald, T., Hollinger, D., Jensed, N.O., Katul, G., Keronen, P., Kowalski, A., Ta Lai, C., Law, B. E., Meyers, T., Moncrieff, J., Moors, E., Munger, J. W., Pilegaards, K., Rannik, Ü., Rebmann, C., Suyker, A., Tenhunen, J., Tu, K., Verma, S., Vesala, T., Wilson, K., and Wofsky, S.: Gap filling strategies for defensible annual sums of net ecosystem exchange, Agr. Forest Meteorol., 107, 43-69, 2001.
Finkelstein, P. L. and Sims, P. F.: Sampling error in eddy correlation flux measurements, J. Geophys. Res.-Atmos., 106, 3503-3509, 2001.

Goulden, M. L., Munger, W. J., Fan, S. M., Daube, B. C., and Wofsy, S. C.: Measurements of carbon sequestration by long-term eddy covariance: methods and a critical evaluation of accuracy, Glob. Change Biol., 2, 169-182, 1996.

Helfter, C., Famulari, D., Phillips, G. J., Barlow, J. F., Wood, C. R., Grimmond, C. S. B., and Nemitz, E.: Controls of carbon dioxide concentrations and fluxes above central London, Atmos. Chem. Phys., 11, 1913-1928, doi:10.5194/acp-11-1913-2011, 2011.

Jain, A. K., Mao, J., and Mohiuddin, K. M.: Artificial Neural Networks: A Tutorial, Computer, 29, 31-44, 1996.

Järvi, L., Hannuniemi, H., Hussein, T., Junninen, H., Aalto, P. P., Hillamo, R., Mäkelä, T., Keronen, P., Siivola, E., Vesala, T., and Kulmala, M.: The urban measurement station SMEAR III: Continuous monitoring of air pollution and surface-atmosphere interactions in Helsinki, Finland, Boreal Environ. Res., 14 (Suppl. A), 86-109, 2009a.

Järvi, L., Mammarella, I., Eugster, W., Ibrom, A., Siivola, E., Dellwik, E., Keronen, P., Burba, G., and Vesala, T.: Comparison of net $\mathrm{CO}_{2}$ fluxes measured with open- and closed-path infrared gas analyzers in urban complex environment, Boreal Environ. Res., 14, 499-514, 2009b.

Järvi, L., Rannik, Ü., Mammarella, I., Sogachev, A., Aalto, P. P., Keronen, P., Siivola, E., Kulmala, M., and Vesala, T.: Annual particle flux observations over a heterogeneous urban area, Atmos. Chem. Phys., 9, 7847-7856, doi:10.5194/acp-9-7847-2009, 2009c.

Jääskeläinen, S.: Climate Policy Programme for the Ministry of Transport and Communications' administrative sector for 20092020 - A progress report 2011, Publications of the Ministry of Transport and Communications, 29/2011 (in Finnish).

Junninen, H., Niska, H., Tuppurainen, K., Ruuskanen, J., and Kolehmainen, M.: Methods for imputation of missing values in air quality data sets, Atmos. Environ., 38, 2895-2907, 2004.

Kolari, P., Kulmala, L., Tupek, B., Alm, J., Hari, P., Ilvesniemi, H., Laine, J., Minkkinen, K., Pumpanen, J., Nikinmaa, E., and Vesala, T.: Photosynthetic production of boreal forest floor vegetation; seasonal and spatial variation, Proceedings of BACCI, NECC and FCoE activities 2005, Book A, Finnish Association for Aerosol Research, 249-254, 2005.

Kolari, P., Kulmala, L., Pumpanen, J., Launiainen, S., Ilvesniemi, H., Hari, P., and Nikinmaa, E.: $\mathrm{CO}_{2}$ exchange and component $\mathrm{CO}_{2}$ fluxes of a boreal Scots pine forest, Boreal Environ. Res., 14, 761-783, 2009.

Kordowski, K. and Kuttler, W.: Carbon dioxide fluxes over an urban park area, Atmos Environ., 45, 2722-2730, 2010.

Kormann, R. and Meixner, F. X.: An analytical footprint model for non-neutral stratification, Bound.-Lay. Meteorol., 99, 207-224, 2001.

Launiainen, S., Rinne, J., Pumpanen, J., Kulmala, L., Kolari, P., Keronen, P., Silvola, E., Pohja, T., Hari, P., and Vesala, T.: Eddy covariance measurements of $\mathrm{CO}_{2}$ and sensible and latent heat fluxes during a full year in a boreal pine forest trunk-space, Boreal Environ. Res., 10, 569-588, 2005.

Lee, X., Massman, W., and Law, B.: Handbook of Micrometeorology, Springer-Verlag New York Inc, 2004. 
Lilleberg, I. and Hellman, T.: The development of traffic in Helsinki in 2010 (in Finnish), Helsinki City Planning Department 2011: 2, 2011.

Liu, H. Z., Feng, J. W., Järvi, L., and Vesala, T.: Four-year (20062009) eddy covariance measurements of $\mathrm{CO}_{2}$ flux over an urban area in Beijing, Atmos. Chem. Phys., 12, 7881-7892, doi:10.5194/acp-12-7881-2012, 2012.

Lounasheimo, J. and Niemi, J.: Helsinki Metropolitan Area Climate Report - Emission Trends in 2009, HSY Helsinki Region Environmental Services Authority, 4/2010 (in Finnish).

Moffat, A. M., Papale, D., Reichstein, M., Hollinger, D. Y., Richardson, A. D., Barr, A. G., Beckstein, C., Braswell, B. H., Churkina, G., Desai, A. R., Falge, E., Gove, J. H., Heimann, M., Hui, D., Jarvis, A. J., Kattge, J., Noormets, A., and Stauch, V. J.: Comprehensive comparison of gap-filling techniques for eddy covariance net carbon fluxes, Agr. Forest Meteorol., 147, 209-232, 2007.

Moriwaki, R. and Kanda, M.: Seasonal and Diurnal Fluxes of Radiation, Heat, Water Vapour, and Carbon Dioxide over a Suburban Area, J. Appl. Meteorol., 43, 1700-1710, 2004.

Nordbo, A., Järvi., L., and Vesala, T.: Revised eddy covariance flux calculation methodologies - effect on urban energy balance, Tellus B, 48, 18184, doi:10.3402/tellusb.v64i0.18184, 2012.

Oke, T. R.: Initial guidance to obtain representative meteorological observations at urban sites, Instruments and observing methods report No. 81, WMO, 2004.

Papale, D. and Valentini, R.: A new assessment of European forests carbon exchanges by eddy fluxes and artificial neural network spatialization. Glob. Change Biol., 9, 525-535, 2003.
Rinne, J., Riutta, T., Pihlatie, M., Aurela, M., Haapanala, S., Tuovinen, J.-P., and Tuittila, E.-S.: Annual cycle of methane emission from a boreal fen measured by the eddy covariance technique, Tellus B, 59, 449-457, 2007.

Rosenzweig, C., Solecki, W., Hammer, S. A., and Mehrotra, S.: Cities lead the way in climate-change action, Nature, 467, 909911, 2010.

Schmidt, A., Wrzesinsky, T., and Klemm, O.: Gap filling and quality assessment of $\mathrm{CO}_{2}$ and water vapour fluxes above an urban area with radial basis function neural networks, Bound.-Lay. Meteorol., 126, 389-413, 2008.

Velasco, E. and Roth, M.: Cities as net sources of $\mathrm{CO}_{2}$ : Review of atmospheric $\mathrm{CO}_{2}$ exchange in urban environments measured by eddy covariance technique, Geography Compass, 4, 1238-1259, 2010.

Vesala, T., Järvi, L., Launiainen, S., Sogachev, A., Rannik, Ü., Mammarella, I., Siivola, E., Keronen, P., Rinne, J., Riikonen, A., and Nikinmaa, E.: Surface-atmosphere interactions over complex urban terrain in Helsinki, Finland, Tellus, 60B, 188-199, 2008.

Vesala, T., Launiainen, S., Kolari, P., Pumpanen, J., Sevanto, S., Hari, P., Nikinmaa, E., Kaski, P., Mannila, H., Ukkonen, E., Piao, S. L., and Ciais, P.: Autumn temperature and carbon balance of a boreal Scots pine forest in Southern Finland, Biogeosciences, 7, 163-176, doi:10.5194/bg-7-163-2010, 2010.

VTT: LIISA2010: Road traffic exhaust emissions calculation software (http://lipasto.vtt.fi/liisa), Technical Research Centre of Finland, VTT, 2011. 